\title{
A neuromusculoskeletal model to simulate the isokinetic ankle dorsiflexion test of spasticity
}

\author{
Ruoli Wang ${ }^{1 *}$, Örjan Ekeberg ${ }^{1}$, Anders Fagergren ${ }^{2}$, Johan Gäverth ${ }^{3}$, Hans Forssberg ${ }^{3}$ \\ From 4th Congress of the International Foot and Ankle Biomechanics (i-FAB) Community \\ Busan, Korea. 8-11 April 2014
}

\section{Introduction}

Spasticity is a motor disorder characterized by a velocitydependent increase in tonic stretch reflexes [1], commonly seen in many neurological disorders. Clinically, spasticity is measured by an examiner rotating a joint and simultaneously estimating the resistance according to an ordinal scale. However, the limited reliability of the measurement and the impossibility to discriminate between the underly- ing neural (stretch reflex) and non-neural (i.e. muscle mechanics) contributions have been the motivation to develop methods describing resistance joint torque quantitatively. The aim of this preliminary study is to develop a forward neuromusculoskeletal model consisting of the explicit musculotendon, muscle spindle, and motoneuron pool, which can simulate the passive isokinetic ankle dorsiflexion test of spasticity.
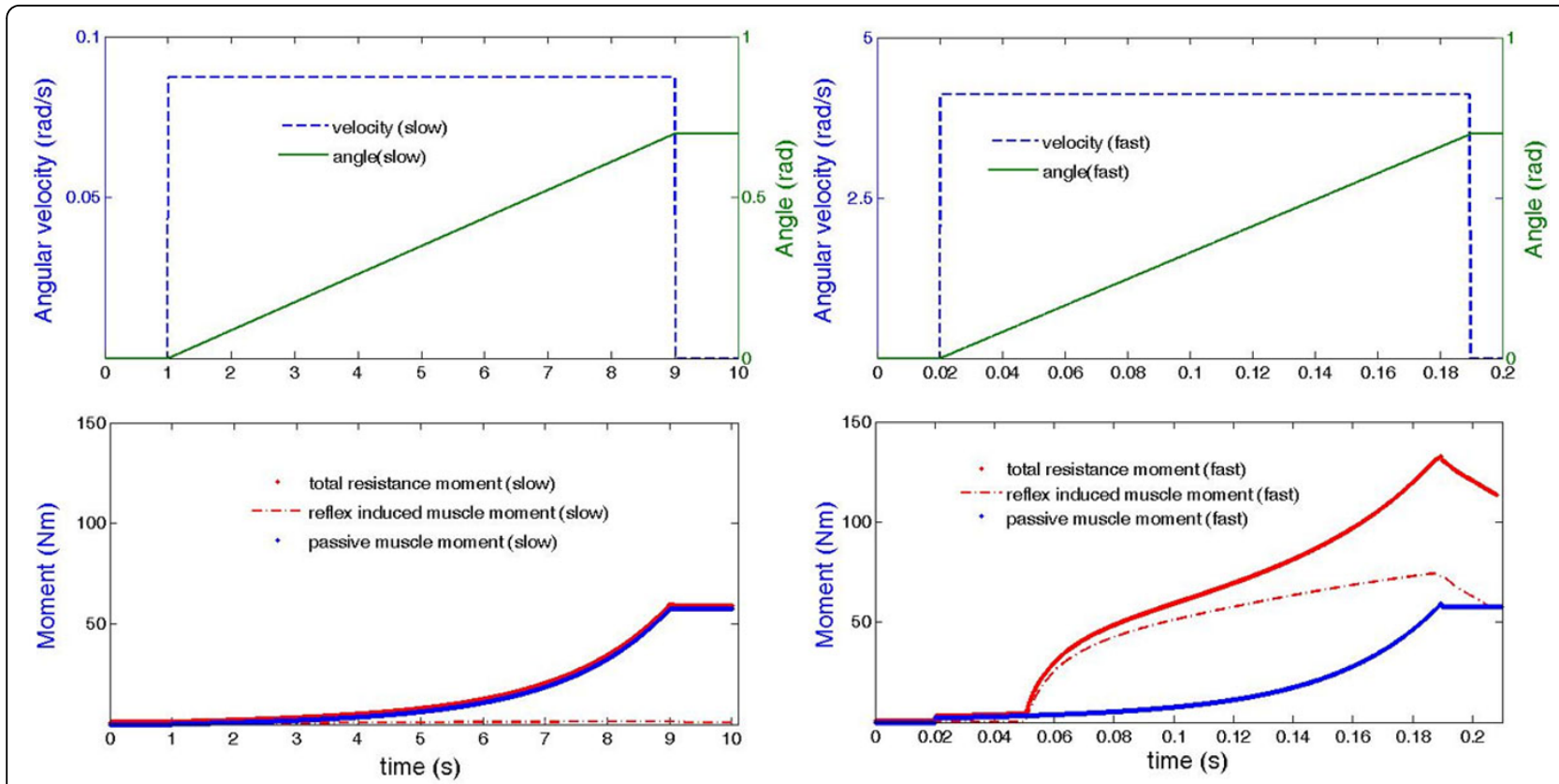

Figure 1 The contributions of the moment from passive muscle properties and the stretch reflex to the total resistance moment when $\alpha$-motoneuron pool properties were specified. The angular velocities and the position of the ankle joint were prescribed in the simulation.

'Department of Computational Biology, KTH Royal Institute of Technology,

Stockholm, Sweden

Full list of author information is available at the end of the article

(c) 2014 Wang et al; licensee BioMed Central Ltd. This is an Open Access article distributed under the terms of the Creative Commons 


\section{Material and methods}

In the model, the plantarflexors were considered as a lumped representation of all the muscles. Dorsiflexors were not included in the model. The musculoskeletal geometry was based on the anthropometrical data from a healthy female (height: $1.62 \mathrm{~m}$, weight: $53 \mathrm{~kg}$ ). The hill-type musculotendon model was used to simulate the musculotendon dynamics of the lumped plantarflexors. Activation dynamics were modeled as a first order differential equation. The hybrid $\mathrm{v}^{0.6}$ model was used to model the firing characteristics of the muscle spindle [2]. The input-output relation of the $\alpha$-motoneuron pool can be simplified as a sigmoid function. The contributions of the moment from the passive muscle properties and the stretch reflex to the total resistance torque were computed from $0^{\circ}$ to $40^{\circ}$ ankle dorsiflexion at two constant angular velocities $\left(5^{\circ} \mathrm{s}^{-1}\right.$ vs. $\left.236^{\circ} \mathrm{s}^{-1}\right)$.

\section{Results and discussions}

Compared to the fast ankle rotation, there was almost no stretch reflex-induced moment in the slow ankle rotation (Figure 1), which agrees to the definition of the spasticity. It indicates that the current neuromusculoskeletal model can describe the individual contributions to the total resistance moment. In the future, by comparing the experimental measurements and the predicted moment, the important spasticity related parameters e.g. $\alpha$-motoneuron pool properties may be identified individually.

\section{Authors' details}

${ }^{1}$ Department of Computational Biology, KTH Royal Institute of Technology, Stockholm, Sweden. ${ }^{2}$ AggeroMedtech AB, Stockholm, Sweden. ${ }^{3}$ Department of Women's and Children's Health, Karolinska Institutet, Stockholm, Sweden.

Published: 8 April 2014

\section{References}

1. Lance J: The control of muscle tone, reflexes, and movement. Neurology 1980, 30:1301.

2. Prochazka A, Gorassini M: Models of ensemble firing of muscle spindle afferents recorded during normal locomotion of cats. J Physiol 1998, 27:21-34. simulate the isokinetic ankle dorsiflexion test of spasticity. Journal of Foot and Ankle Research 2014 7(Suppl 1):A87.

\section{Submit your next manuscript to BioMed Central} and take full advantage of:

- Convenient online submission

- Thorough peer review

- No space constraints or color figure charges

- Immediate publication on acceptance

- Inclusion in PubMed, CAS, Scopus and Google Scholar

- Research which is freely available for redistribution

Submit your manuscript at www.biomedcentral.com/submit 